\title{
Differentiation of Benign and Malignant Solitary Pulmonary Nodule: Literature Review
}

\author{
Suresh Tripathi' ${ }^{1}$ Xuqiu Zhen ${ }^{2 *}$ \\ ${ }^{1}$ School of Medicine, South East University, Nanjing, China \\ ${ }^{2}$ Department of Radiology Zhongda Hospital, South East University, Nanjing, China \\ Email: 'xuqiuzhen831@sina.com
}

Received 20 May 2015; accepted 27 June 2015; published 30 June 2015

Copyright (C) 2015 by authors and Scientific Research Publishing Inc.

This work is licensed under the Creative Commons Attribution International License (CC BY). http://creativecommons.org/licenses/by/4.0/

(c) (i) Open Access

\section{Abstract}

The solitary pulmonary nodule (SPN) is frequently seen on chest radiographs and computed tomography (CT), usually the identification is accidental. The overall prevalence of malignancy is relatively low but identification of malignancy of nodule is of prime importance. There are different characters of nodules indicating malignancy, and also the exposure of person to risk factors increases the chances of malignancy of nodule. Chances of malignancy rise with increasing size, the irregular, lobulated border of the nodules is highly associated with higher probability of malignancy and nodules with pure ground grass appearance have higher probability of malignancy, irregularly marginated nodule displaying a corona radiata sign indicating neoplastic infiltration with distortion of neighbouring tissue is almost certainly a malignant nodule. Stippled, punctuate, and eccentric calcifications are suggestive of malignancy. There are $20 \%-75 \%$ of chances of malignancy if nodule is appeared with ground-glass opacity. Malignant nodules have higher growth rate as compared with benign nodules, malignant nodules usually have doubling time (DT) of 30 $\mathbf{4 0 0}$ days while DT of more than 450 days is sign of benignity whereas doubling time less than $\mathbf{3 0}$ days is usually acute infectious process. The presence of fat within nodule is sign of benignity. Increasing density of the nodule is suggestive of malignancy and requires shorter follow up. Besides the nodule evaluation the chances of malignancy can also be evaluated through the exposure of patient to risk factors like age, current and past smoking status and history of extra thoracic malignancy. The management depends upon various factors mainly three strategies are applied for management including careful observation of nodule, use of diagnostic techniques like CT FNA, PET, and broncoscopy and surgery.

"Corresponding author. 
Keywords

Solitary Pulmonary Nodule (SPN), Benign Pulmonary Nodule, Malignant Pulmonary Nodule, CT

\section{Introduction}

A solitary pulmonary nodule (SPN) is defined as an approximately round lesion less than $3 \mathrm{~cm}$ in diameter that is completely surrounded by pulmonary parenchyma without other pulmonary abnormalities [1]. The term "solitary pulmonary nodule" was coined when most nodules were detected incidentally by chest radiography and were solitary. Today, most nodules are detected by CT, which greatly enhances nodule detection and characterization. Thus, the classical definition of pulmonary nodules now needs to be updated to integrate data from CT studies. [2] An SPN is found on $0.09 \%$ to $0.20 \%$ of all chest radiographs, and an estimated 150,000 such nodules are identified each year in the United States [1] [3]. The differentiation of solitary pulmonary nodules (SPNs) as benign or malignant remains a diagnostic challenge for thoracic radiology [4]. During the past decade, promising results for more specific differentiation of malignant and benign nodules using dynamic contrast material-enhanced CT have been reported [5] [6]. The significance of pulmonary nodules is variable, dependent first and foremost on the clinical context. In a patient with known primary malignancy, lung nodules, regardless of being solitary or multiple, would be deemed suspicious for metastases; whereas in a patient with no reported respiratory symptom or risk factor such as smoking history, a solitary nodule may be incidental and benign. The United States National Lung Cancer Screening Trial reported high false positive rates with low-dose CT screening, due to benign intrapulmonary nodes and non-calcified granulomas [7]. Lung nodules are a common problem in pulmonary practice. Estimates of their frequency range from $0.2 \%$ in older studies with chest radiographs to approximately $40 \%-60 \%$ in lung cancer screening trials using low-dose computed tomography (CT) [1] [8], another finding with review of eight large lung cancer screening trials revealed a variable prevalence rate of at least one nodule to be $8 \%$ - $51 \%$ of which $1.1 \%$ - $12 \%$ were malignant [3]. The first concern regarding SPNs is the exclusion of malignancy. The majority of incidental and screen-detected nodules are benign granulomas (both healed and active) (40\%) and hematomas (15\%) [9]. Management of a SPN begins with evaluation of the patient's history and risk assessment followed by morphological review of the SPN. Depending on the appearance and radiologic context, certain SPNs are judged sufficiently typical of benign masses that follow-up is not warranted. Important factors that suggest benignity is the presence of characteristic calcification, the presence of fat with the SPN, the size, rate of growth certain characteristics such as SPN margins [10].

\section{Literature Review}

The important part in the nodule management is determination of nodule whether it is benign or is malignant. Features like size, margins, calcification, attenuation, growth rate, cavitation, presence of fat, ground glass opacity, density etc often help to determine the likelihood of nodule. Common causes of benign nodule include include infectious granulomas and hamartomas, whereas common malignant causes include primary lung cancer, carcinoid tumors, and lung metastases [9] [11].

\subsection{Radiological Evaluation}

The variables to assess with CT are the nodule's size, border characteristics, and density [2]. The probability of malignancy varies with size. For subcentimeter pulmonary nodules, the overall prevalence of malignancy is relatively low. Wahidi MM et al. (2007) In seven studies of nodules detected in lung cancer screening trials, the prevalence of malignancy was $0 \%-1 \%$ in patients with nodules less than $5 \mathrm{~mm}$ in diameter, $6 \%-28 \%$ for 5 - to 10 -mm nodules, $33 \%-64 \%$ for 11 - to 20 -mm nodules, and $64 \%-82 \%$ for nodules measuring greater than 20 $\mathrm{mm}$ [3].

Border characteristics can also be used to help estimate the probability of malignancy. Nodules with irregular, lobulated, or speculated borders are associated with a progressively higher probability of malignancy than those with a smooth border. Similarly, nodules with a pure ground-glass or semisolid appearance have a higher probability of malignancy than pure solid lesions [3]. 


\subsubsection{Size}

There are higher chances of malignancy with increasing size of nodule. Small solitary pulmonary nodules are likely to be benign. A screening study by Henschke et al. in 2004 found that none of the detected malignancies were less than $5 \mathrm{~mm}$ in diameter [10] The prevalence of malignancy correlates with nodule size (0\% - $1 \%$ for nodules $/ 5 \mathrm{~mm}, 6 \%$ - 28\% for nodules 5 - $10 \mathrm{~mm}$, 33\% - 60\% for nodules 11 - $20 \mathrm{~mm}$, and 64\% - 82\% for nodules greater than $20 \mathrm{~mm}$ ) [9] [13].

\subsubsection{Margins}

Margins are classified as smooth, lobulated, spiculated, or irregular. Lobulated contour, signifying uneven growth, is often associated with malignant nodules but can be seen in $25 \%$ of benign nodules [14] [15] Although most smoothly marginated nodules are benign but up to $21 \%$ of malignant nodules may have this feature [14] A spiculated or irregularly marginated nodule displaying a corona radiata sign indicating neoplastic infiltration and distortion on neighboring tissues is almost certainly a sign of malignancy.

\subsubsection{Calcifications}

Calcifications are more frequent in benign SPNs. Fishman AP et al. (1988) shows patterns of calcification characteristic of benign nodules are laminated, dense central, and popcorn whereas stippled, punctuate, and eccentric calcifications are suggestive of malignancy [16].

\subsubsection{Attenuation}

Ground-glass attenuation at CT is a characteristic that has been associated with a subset of nodules representing primary lung malignancy, more specifically adenocarcinoma. Anywhere from $20 \%$ to $75 \%$ of ground-glass nodules are malignant [9] [17]. The ground-glass component represents lepidic growth or mucin production. Aoki et al. (2000) showed that increasing solid components within a ground-glass nodule correlated with more aggressive behavior [18] a screening study by Henschke et al. showed a higher rate of malignancy among mixed SPNs (63\%) compared with nonsolid (18\%) and solid SPNs (7\%) [19].

\subsubsection{Growth Rate (Volume Doubling Time)}

Volume doubling time (DT) is the time required for a nodule to double in volume. For most malignant SPNs, DT is between 30 and 400 days and corresponds to a $26 \%$ increase in diameter. DT may be used to stratify nodules into different categories with differing probabilities for malignancy. For example, nodules with a DT less than 20 - 30 days are usually acute infectious processes. Slow growing nodules with DT greater than 450 days are likely to be benign. Lack of two-year growth on chest imaging was thought to confirm benignity. However, this longstanding dictum on categorization of nodules based on growth measurement has been challenged. Hasegawa et al. (2000) reported the DT for malignant SPNs on the basis of their morphologic features: $813 \pm 375$ days for pure ground-glass opacities, $457 \pm 260$ days for mixed or partial ground-glass opacities, and $149 \pm 125$ days for solid nodules. From these data, the two-year stability rule signifying benignity is no longer valid, particularly for pure ground-glass or predominately ground-glass nodules. Preliminary results from a retrospective review of ground-glass attenuation nodules at NYU Langone Medical Center over an 8-year period (2003-2011) showed that $23 \%$ of nodules progressed (in size, attenuation, or both) in a median of 14.8 months, with the time to progression as short as 2.8 months and as long as 61.4 months (5 years). Stable ground-glass nodules were followed for a median of 45.8 months [20].

\subsubsection{Cavitations}

Cavitations may be seen with both benign and malignant nodules. Unfortunately, the thickness of the wall is unreliable in distinguishing benign from malignant, although malignancy is associated with thicker and more irregular walls. Pseudocavitation is a descriptor frequently used in describing features of bronchioloalveolar carcinoma (BAC). It is the result of lepidic growth, not necrosis, as tumor cells grow along the lung scaffolding sparing the alveoli. Diagnostic considerations for cavitary nodules include pulmonary infarct, fungal infection, Wegner granulomatosis, and solitary metastasis.

\subsubsection{Fat within Nodule}

The presence of fat within a SPN is a reliable sign of benignity [21]. Fat-containing lung lesions include pulmo- 
nary hamartoma, lipoid pneumonia, and lipoma. Endobronchial pulmonary hamartoma usually appears at CT as a lesion with a smooth edge, focal collections of fat that alternate with foci of calcification. An air cleft on the side or the inside is characteristic of pulmonary hamartoma. Pulmonary artery branches connect beyond half of pulmonary hamartoma. This finding suggests close relations in the bronchus along the artery. It is important that there is no connection of the pulmonary vein, to differentiate it from a bronchogenic carcinoma [22] [23]. The majority of pulmonary hamartomas present an SPN. Peripheral tumors are usually simply observed after the definitive diagnosis; central tumors may be excised [24] [25].

\subsubsection{Appearance of Ground Glass Opacity (GGO) Nodules in CT}

Various studies found lesions appearing as nodular ground-glass opacity at CT are highly potential for developing bronchioloalveolar carcinoma and early stage adenocarcinoma than that of solid nodules [26] [27] which also correlates with finding of study by Lee et al. (2007) [28]. The malignancy rate of nodular ground glass opacity with solid component within it was also found to be 93\% [29]. Henschke et al. (2002) found malignancy rates among findings of nodular ground-glass opacity for lesions with and without a solid component as 63\% and $18 \%$ respectively [19]. Persistent finding of nodular ground glass opacity in CT is highly suggestive of neplastic condition.

Over the last few decades, studies of screening-detected and incidentally detected peripheral adenocarcinomas have clarified associations between CT characteristics, histopathology, growth rates, and clinical outcomes [27] [30].

\subsubsection{CT Densitometry}

High-density SPNs demonstrated on CT, which appeared non-calcified on conventional tomography, are considered benign. Siegelman et al. (1980) suggested 164 Hounsfield units as threshold above which the nodules are considered benign. It was presumed that diffuse calcification likely accounts for the higher CT numbers of some benign lesions [14].

Xu DM et al. (2009) concluded that baseline nodule density and changes in nodule features cannot be used to discriminate between benign and malignant solid indeterminate pulmonary nodules, but an increase in density is suggestive for malignancy and required a shorter follow-up or a biopsy [31].

\subsection{Risk Assessment}

Calculating the risk of malignancy of an SPN requires not only analysis of nodule size, morphology, location, and growth rate but also defining patient's underlying risk factors. Independent predictors of malignancy include age, current or past smoking, history of extra thoracic malignancy, nodule diameter, spiculation, and upper lobe location [32] [33]. Specific clinical features determined to be significant predictors of malignancy are age, smoking history, and personal history of cancer 5 or more years prior [33].

\subsubsection{Clinical Risk Factors}

The clinical assessment includes the patient's history and physical examination. Clinical risk factors associated with a higher probability of malignancy are, nodule size more than $20 \mathrm{~mm}$, age more than 60 years, prior cancer history, smoker, exposure to asbestos, speculated nodule [2].

\subsubsection{Management}

The management of a SPN begins with evaluation of the patient's history and risk assessment followed by morphological review of the SPN. Depending on the appearance and radiologic context, certain SPNs are judged sufficiently typical of benign masses that follow-up is not warranted. Important factors that suggest benignity is the presence of characteristic calcification, the presence of fat with the SPN, the size, rate of growth certain characteristics such as SPN margins [10].

\subsubsection{Strategies for Management}

Three key strategies will be helpful in managing a solitary pulmonary nodule includes, careful observation, diagnostic testing and surgery. For each it is suggested when the strategy should be used, the evidence in support of the strategy, its limitations, and areas of uncertainty. 


\section{1) Careful Observation}

Careful observation usually involves radiologic surveillance with serial CT and is most appropriate when the pretest probability of malignancy is relatively low $(<5 \%-10 \%)$ [9]. Most malignant lesions double in volume every 20 to 300 days leading to the clinical axiom that radiographic stability for 2 years suggests benign etiology [9] [40]. This is assumed that growth rates, measured radiographically, can be used to distinguish benign from malignant nodules [3] [8]. The primary weakness of this strategy is the hazard of delay; specifically, the probability that a previously curable lesion would metastasize during the period of observation [12] [34].

\section{2) Diagnostic Testing}

When the probability of malignancy is intermediate (z10-60\%), a diagnostic test is usually warranted. The main options are positron emission tomography (PET), CT-FNA, and bronchoscopy.

PET: The sensitivity and specificity of PET for identifying malignancy are approximately $87 \%$ and $83 \%$, respectively [3] [9]. PET has a high negative predictive value when the pretest probability of cancer is low, and such patients can be subsequently managed with careful observation. PET does have important limitations. First, PET is less sensitive for nodules less than 8 - $10 \mathrm{~mm}$ in diameter [35]-[37] also, false-negative PET scans can be seen in patients with adenocarcinoma in situ, carcinoid tumors, and mucinous adenocarcinomas. False positive PET scans can be seen in patients with inflammatory conditions (sarcoidosis or rheumatoid nodules) or infectious processes (endemic mycosis or mycobacterial infection). However, occasionally PET demonstrates evidence of lymph node involvement or extrapulmonary disease that might not otherwise have been detected [38] [39].

CT guided FNA Cytology: CT-FNA has been shown to have reasonable sensitivity for identifying malignant lung nodules. In 11 studies, counting non-diagnostic results as false-negatives, the median sensitivity was 90\% [3].

Broncoscopy: Although bronchoscopy is useful for central lesions, it has proved less accurate for peripheral pulmonary nodules. Studies using traditional techniques, such as conventional fluoroscopic guidance, demonstrated diagnostic yields of $10 \%-50 \%$ overall and approximately 33\% for peripheral lesions less than $20 \mathrm{~mm}$ in diameter [41].

\section{3) Surgery}

Video-assisted thoracic surgery, traditional thoracotomy, and sometimes a combination may be warranted when the probability of cancer is high $(60 \%-70 \%)$, both to establish a diagnosis and for definitive treatment. The risk of surgery depends on whether the nodule resected is malignant. If the nodule is found to be benign at frozen section, then only a wedge resection is required, and operative mortality is typically low $(\approx 0.5 \%)$ [9] [41] [42] if the nodule is found to be malignant, then a lobectomy with systematic lymph node dissection is preferred. Lobectomy mortality has been reported to be $1 \%$ - 4\% [41] [42].

\section{Conclusion}

The identification of nodule is mostly accidental in chest radiography. Identification of character of nodule is important for management. The diagnosis of nodule involves both clinical and imaging assessment including risk assessment and morphology of the nodule. Emphasis should be placed on accurate diagnosis using the least possible resources avoiding surgical intervention where possible and the judicious use of biopsy procedures. Full use of newer techniques should play a part where available. Accurate diagnosis of nodule is made through its various characters and associated risk factors. The management strategies include careful observation of nodule with CT scan, other diagnostic tests like CT-FNA, PET and broncoscopy and surgery. Each of these components have own limitations and clinician should be aware of the limitations.

\section{References}

[1] Ost, D., Fein, A.M. and Feinsilver, S.H. (2003) The Solitary Pulmonary Nodule. The New England Journal of Medicine, 348, 2535-2542. http://dx.doi.org/10.1056/NEJMcp012290

[2] Ost, D.E. and Gould, M.K. (2012) Decision Making in Patients with Pulmonary Nodules. American Journal of Respiratory and Critical Care Medicine, 185, 363-372.

[3] Wahidi, M.M., Govert, J.A., Goudar, P.K., et al. (2007) Evidence for the Treatment of Patients with Pulmonary Nodules: When Is It Lung Cancer? ACCP Evidence-Based Clinical Practice Guidelines (2nd Edition). Chest, 132, 94S$107 \mathrm{~S}$. 
[4] Khan, A., Herman, P.G., Vorwerk, P., Stevens, P., Rojas, K.A. and Graver, M. (1991) Solitary Pulmonary Nodules: Comparison of Classification with Standard, Thin-Section, and Reference Phantom CT. Radiology, 179, 477-481. http://dx.doi.org/10.1148/radiology.179.2.2014295

[5] Yamashita, K., Matsunobe, S., Tsuda, T., et al. (1995) Solitary Pulmonary Nodules: Preliminary Study of Evaluation with Incremental Dynamic CT. Radiology, 194, 399-405. http://dx.doi.org/10.1148/radiology.194.2.7824717

[6] Yi, C.A., Lee, K.S., Kim, E.A., Han, J., Kim, H., Kwory, O.J., et al. (2004) Solitary Pulmonary Nodules: Dynamic Enhanced Multi-Detector Row CT Study and Comparison with Vascular Endothelial Growth Factor and Microvessel Density. Radiology, 233, 191-199. http://dx.doi.org/10.1148/radiol.2331031535

[7] National Lung Screening Trial Research Team, Aberle, D.R., Adams, A.M., et al. (2011) Reduced lung-Cancer Mortality with Low-Dose Computed Tomographic Screening. The New England Journal of Medicine, 365, 395-409. http://dx.doi.org/10.1056/NEJMoa1102873

[8] Van Klaveren, R.J., Oudkerk, M., Prokop, M., Scholten, E.T., Nackaerts, K., Vernhout, R., van Iersel, C.A., van den Bergh, K.A., van’t Westeinde, S., van der Aalst, C., et al. (2009) Management of Lung Nodules Detected by Volume CT Scanning. The New England Journal of Medicine, 361, 2221-2229. http://dx.doi.org/10.1056/NEJMoa0906085

[9] Gould, M.K., Fletcher, J., Iannettoni, M.D., et al. (2007) Evaluation of Patients with Pulmonary Nodules: When Is It Lung Cancer? ACCP Evidence-Based Clinical Practice Guidelines (2nd Edition). Chest, 132, 108S-130S.

[10] Jeong, Y.J., Yi, C.A. and Lee, K.S. (2007) Solitary Pulmonary Nodules: Detection, Characterization, and Guidance for Further Diagnostic Workup and Treatment. American Journal of Roentgenology, 188, 57-68. http://dx.doi.org/10.2214/AJR.05.2131

[11] Tozaki, M., Ichiba, N. and Fukuda, K. (2005) Dynamic Magnetic Resonance Imaging of Solitary Pulmonary Nodules: Utility of Kinetic Patterns in Differential Diagnosis. Journal of Computer Assisted Tomography, 29, 13-19. http://dx.doi.org/10.1097/01.rct.0000153287.79730.9b

[12] Henschke, C.I., Yankelevitz, D.F., Naidich, D.P., et al. (2004) CT Screening for Lung Cancer: Suspiciousness of Nodules According to Size on Baseline Scans. Radiology, 231, 164-168. http://dx.doi.org/10.1148/radiol.2311030634

[13] Darrow, J.C. and Lack, E.E. (1981) Solitary Lung Nodule Due to Dirofilaria immitis (Dog “Heartworm”). Journal of Surgical Oncology, 16, 219-224.

[14] Siegleman, S.S., Zerhouni, E.A., Leo, F.P., et al. (1980) CT of the Solitary Pulmonary Nodule. American Journal of Roentgenology, 135, 1-13. http://dx.doi.org/10.2214/ajr.135.1.1

[15] Zwirewich, C.V., Vedal, S., Miller, R.R., et al. (1991) Solitary Pulmonary Nodule: High-Resolution CT and Radiologic-Pathologic Correlation. Radiology, 179, 469-476. http://dx.doi.org/10.1148/radiology.179.2.2014294

[16] Fishman, A.P. (1988) Pulmonary Disease and Disorders. 2nd Edition, McGraw-Hill, New York, 1947.

[17] Kim, H.Y., Shim, Y.M., Lee, K.S., et al. (2007) Persistent Pulmonary Nodular Ground-Glass Opacity at Thin-Section CT: Histopathologic Comparisons. Radiology, 245, 267-275. http://dx.doi.org/10.1148/radiol.2451061682

[18] Aoki, T., Nakata, H., Watanabe, H., et al. (2000) Evolution of Peripheral Adenocarcinomas: CT Findings Correlated with Histology and Tumor Doubling Time. American Journal of Roentgenology, 174, 763-768. http://dx.doi.org/10.2214/ajr.174.3.1740763

[19] Henschke, C.I., Yankelevitz, D.F., Mirtcheva, R., et al. (2002) CT Screening for Lung Cancer: Frequency and Significance of Part-Solid and Nonsolid Nodules. American Journal of Roentgenology, 178, 1053-1057. http://dx.doi.org/10.2214/ajr.178.5.1781053

[20] Hasegawa, M., Sone, S., Takashima, S., et al. (2000) Growth Rates of Small Lung Cancers Detected on Mass CT Screening. The British Journal of Radiology, 73, 1252-1259. http://dx.doi.org/10.1259/bjr.73.876.11205667

[21] Caskey, C.I., Templeton, P.A. and Zerhouni, E.A. (1990) Current Evaluation of the Solitary Pulmonary Nodule. Radiologic Clinics of North America, 28, 511-520.

[22] Kanauchi, T., Hoshi, T. and Kato, A. (2004) CT Findings of Pulmonary Hamartoma with Special Reference to epithelial-Lined Clefts and Connection with Pulmonary Arteries. Nihon Igaku Hoshasen Gakkai Zasshi, 64, 300-304

[23] Park, K.Y., Kim, S.J., Noh, T.W., Cho, S.H., Lee, D.Y., Paik, H.C., et al. (2008) Diagnostic Efficacy and Characteristic Features of MRI in Pulmonary Hamartoma: Comparison with CT, MRI and Pathology. Journal of Computer Assisted Tomography, 32, 919-925. http://dx.doi.org/10.1097/RCT.0b013e31815abed4

[24] Lien, Y.C., Hsu, H.S., Li, W.Y., Wu, Y.C., Hsu, W.H., Wang, L.S., et al. (2004) Pulmonary Hamartoma. Journal of the Chinese Medical Association, 67, 21-26.

[25] Guo, W., Zhao, Y.P., Jiang, Y.G., Wang, R.W. and Ma, Z. (2008) Surgical Treatment and Outcome of Pulmonary Hamartoma: Retrospective Study of 20-Year Experience. Journal of Experimental \& Clinical Cancer Research, 27, 8. http://dx.doi.org/10.1186/1756-9966-27-8 
[26] Takashima, S., Sone, S., Li, F., et al. (2003) Small solitary Pulmonary Nodules ( $\leq 1 \mathrm{~cm})$ Detected at Population-Based CT Screening for Lung Cancer: Reliable High-Resolution CT Features of Benign Lesions. American Journal of Roentgenology, 180, 955-964. http://dx.doi.org/10.2214/ajr.180.4.1800955

[27] Noguchi, M., Morikawa, A., Kawasaki, M., et al. (1995) Small Adenocarcinoma of the Lung. Cancer, 75, $2844-2852$. http://dx.doi.org/10.1002/1097-0142(19950615)75:12<2844::AID-CNCR2820751209>3.0.CO;2-\#

[28] Lee, H.J., Goo, J.M., Lee, C.H., Yoo, C.G., Kim, Y.T. and Im, J.G. (2007) Nodular Ground-Glass Opacities on Thin-Section CT: Size Change during Follow-Up and Pathological Results. Korean Journal of Radiology, 8, 22-31. http://dx.doi.org/10.3348/kjr.2007.8.1.22

[29] Nakata, M., Saeki, H., Takata, I., et al. (2002) Focal Ground-Glass Opacity Detected by Low-Dose Helical CT. Chest, 121, 1464-1467. http://dx.doi.org/10.1378/chest.121.5.1464

[30] Godoy, M.C. and Naidich, D.P. (2009) Subsolid Pulmonary Nodules and the Spectrum of Peripheral Adenocarcinomas of the Lung: Recommended Interim Guidelines for Assessment and Management. Radiology, 253, 606-622. http://dx.doi.org/10.1148/radiol.2533090179

[31] Xu, D.M., van Klaveren, R.J., de Bock, G.H., Leusveld, A.L., Dorrius, M.D., Zhao, Y., et al. (2009) Role of Baseline Nodule Density and Changes in Density and Nodule Features in the Discrimination between benign and Malignant Solid Indeterminate Pulmonary Nodules. European Journal of Radiology, 70, 492-498. http://dx.doi.org/10.1016/j.ejrad.2008.02.022

[32] Herder, G.J., van Tinteren, H., Goldberg, R.P., et al. (2005) Clinical Prediction Model to Characterize Pulmonary Nodules: Validation and Added Value of 18-F-FDG Positron Emission Tomography. Chest, 128, 2490-2496. http://dx.doi.org/10.1378/chest.128.4.2490

[33] Swensen, S.J., Silverstein, M.D., Ilstrup, D.M., et al. (1997) The Probability of Malignancy in Solitary Pulmonary Nodules, Application to Small Radiologically Indeterminate Nodules. Archives of Internal Medicine, 157, 849-855. http://dx.doi.org/10.1001/archinte.1997.00440290031002

[34] MacMahon, H., Austin, J.H., Gamsu, G., Herold, C.J., Jett, J.R., Naidich, D.P., Patz Jr., E.F. and Swensen, S.J. (2005) Guidelines for Management of Small pulmonary Nodules Detected on CT Scans: A Statement from the Fleischner Society. Radiology, 237, 395-400. http://dx.doi.org/10.1148/radiol.2372041887

[35] Ost, D. and Fein, A. (2000) Evaluation and Management of the Solitary Pulmonary Nodule. American Journal of Respiratory and Critical Care Medicine, 162, 782-787. http://dx.doi.org/10.1164/ajrccm.162.3.9812152

[36] Ost, D. and Fein, A. (2004) Management Strategies for the Solitary Pulmonary Nodule. Current Opinion in Pulmonary Medicine, 10, 272-278. http://dx.doi.org/10.1097/01.mcp.0000130322.11513.c8

[37] Herder, G.J., Golding, R.P., Hoekstra, O.S., Comans, E.F., Teule, G.J., Postmus, P.E. and Smit, E.F. (2004) The Performance of ${ }^{18}$ F-Fluorodeoxyglucose Positron Emission Tomography in Small Solitary Pulmonary Nodules. European Journal of Nuclear Medicine and Molecular Imaging, 31, 1231-1236. http://dx.doi.org/10.1007/s00259-004-1552-7

[38] Weder, W., Schmid, R.A., Bruchhaus, H., Hillinger, S., von Schulthess, G.K. and Steinert, H.C. (1998) Detection of Extrathoracic Metastases by Positron Emission Tomography in Lung Cancer. The Annals of Thoracic Surgery, 66, 886-892.

[39] Niho, S., Fujii, H., Murakami, K., Nagase, S., Yoh, K., Goto, K., Ohmatsu, H., Kubota, K., Sekiguchi, R., Nawano, S., et al. (2007) Detection of Unsuspected Distant Metastases and/or Regional Nodes by FDG-PET (Corrected) Scan in Apparent Limited-Disease Small-Cell Lung Cancer. Lung Cancer, 57, 328-333. http://dx.doi.org/10.1016/j.lungcan.2007.04.001

[40] Schreiber, G. and McCrory, D.C. (2003) Performance Characteristics of Different Modalities for Diagnosis of Suspected Lung Cancer: Summary of Published Evidence. Chest, 123, 115S-128S. http://dx.doi.org/10.1378/chest.123.1_suppl.115S

[41] Freixinet, J.L., Varela, G., Molins, L., Rivas, J.J., Rodríguez-Paniagua, J.M., de Castro, P.L., Izquierdo, J.M. and Torres, J. (2011) Benchmarking in Thoracic Surgery. European Journal Cardio-Thoracic Surgery, 40, 124-129. http://dx.doi.org/10.1016/j.ejcts.2010.10.010

[42] Matsubara, Y., Takeda, S. and Mashimo, T. (2005) Risk Stratification for Lung Cancer Surgery: Impact of Induction Therapy and Extended Resection. Chest, 128, 3519-3525. http://dx.doi.org/10.1378/chest.128.5.3519 


\section{Abbreviations}

SPN: Solitary Pulmonary Nodule PET: positron emission tomography CT: Computed Tomography CT-FNA: CT-Fine Needle Aspiration BAC: Broncholveolar Carcinona GGO: Ground Glass Opacity 